\title{
A parametric study on isobaric adsorption process in a closed adsorbent bed ${ }^{\text {t }}$
}

\author{
Gamze Gediz Ilis ${ }^{\text {a }}$, Moghtada Mobedi ${ }^{\text {a,* }}$, Semra Ülkü ${ }^{\mathrm{b}}$ \\ a Mechanical Engineering Department, Izmir Institute of Technology, Urla 35430, Izmir, Turkey \\ b Chemical Engineering Department, Izmir Institute of Technology, Urla 35430, Izmir, Turkey
}

\section{A R T I C L E I N F O}

Available online 4 February 2010

\section{Keywords:}

Adsorption

Adsorption heat pump

Heat and mass transfer

\begin{abstract}
A B S T R A C T
A numerical study on heat and mass transfer in an annular adsorbent bed filled with adsorbent granules for an isobaric adsorption process is performed. In order to reduce the number of independent parameters that influences heat and mass transfer in the bed, the governing equations and related initial and boundary conditions for the problem are non-dimensionalized and this yields two dimensionless parameters as $G$ and $\Gamma$. The $G$ dimensionless parameter is the ratio of heat of adsorption to sensible heat stored by adsorbent particle and $\Gamma$ parameter compares mass diffusion within the adsorbent particle and heat diffusion in the radial direction of the adsorbent bed. The obtained results show that the total dimensionless time for an adsorption process can be reduced by increasing of $\Gamma$ value. The total dimensionless time is independent from $G$ for low values of $\Gamma$ (i.e. $\Gamma=10^{-5}$ ). The results also show that the instantaneous equilibrium model can provide accurate results only for an adsorbent bed with a low value of $\Gamma$ (i.e. $\Gamma=10^{-5}$ ). The present study is performed for $\Gamma$ values from $10^{-5}$ to 1 and $G$ value from 1 to 100 .
\end{abstract}

(c) 2010 Elsevier Ltd. All rights reserved.

\section{Introduction}

Adsorption technology has a wide application in industry such as pollution control and gas separation. Adsorption of a gas is an exothermic process whereas the reverse process, desorption, is an endothermic one. Recently, adsorption based heat storage and refrigeration systems have gained the attention of researchers. The utilization of the adsorption-desorption cycle was first proposed by Close [1] who had obtained warm and relatively dry air by using a silica gel adsorbent bed. After that, a solar refrigerator was constructed by Tchernev [2,3] and then the adsorption heat pump has gained special emphasis.

Generally, adsorbent beds can be classified into two groups as closed and open beds. An open adsorbent bed can be a packed or fluidized bed with one or more inlets and outlets for adsorptive flow. It generally operates under atmospheric pressure. However, a closed type bed operates under low or high pressure which requires a closed shell [4]. The adsorbent bed used in the adsorption heat pump is a closed type and it enables the combination of heat storage and heat pumping functions in the same system. Studies on adsorption heat pump have increased considerably due to its advantages such as operation with low level temperature heat reservoir, utilization of waste heat and alternative energy sources such as solar or geothermal energies.

\footnotetext{
is Communicated by W.J. Minkowycz.

* Corresponding author.

E-mail address: moghtadamobedi@iyte.edu.tr (M. Mobedi).
}

Two kinds of mass transfer occur in a granular adsorbent bed; mass transfer within the adsorbent particle (intraparticle mass transfer) and mass transfer through the adsorbent bed (interparticle mass transfer). The interparticle mass transfer mostly occurs due to the pressure difference of adsorptive in the adsorbent bed. The intraparticle mass transfer is generally formed by diffusion mode of transport. The rate of heat and mass transfer in an adsorbent bed of adsorption heat pump depends on many parameters such as particle size, thermal and mass diffusivity, porosity, thermal conductivity and adsorption equilibria of adsorbent-adsorbate pair, etc. The theoretical or experimental study on the effects of all these parameters for an adsorption or desorption process is complex. The non-dimensionalization of governing equations can reduce the number of independent parameters and simplify understanding of their effects on the adsorption or desorption process. Although the number of dimensional theoretical studies on heat and mass transfer in adsorbent bed of adsorption heat pump is considerable [5-9], limited dimensionless studies have been performed. Leong and Liu [10] numerically studied heat and mass recovery adsorption cooling cycle to investigate the effects of system design and operation parameters on the performance of cycle. Heat and mass transfer equations for adsorbent bed and mass transfer equation for adsorbent particle are non-dimensionalized in their study. Cacciola et al. [11] performed a study on dynamic simulation of recuperative adsorption heat pump. They used uniform temperature and pressure model and made the governing equations dimensionless to find the variations of temperatures of reactors, condenser and evaporator and to determine thermal power during system operation. Marletta et al. [12] employed a non-uniform temperature and pressure model for heat and mass transfer in 


\begin{tabular}{|c|c|}
\hline \multicolumn{2}{|c|}{ Nomenclature } \\
\hline$C_{\mathrm{p}}$ & Specific heat of adsorbent, $\mathrm{J} / \mathrm{Kg} \mathrm{K}$ \\
\hline$D_{\text {eff }}$ & Effective diffusivity, $\mathrm{m}^{2} / \mathrm{s}$ \\
\hline$P$ & Pressure, Pa \\
\hline$P_{\mathrm{s}}$ & Saturation pressure, $\mathrm{Pa}$ \\
\hline$r_{\mathrm{p}}$ & Radius of adsorbent granule, $\mathrm{m}$ \\
\hline$R$ & Radius of bed, $\mathrm{m}$ \\
\hline$T$ & Temperature, K \\
\hline$t$ & Time, sec \\
\hline $\bar{W}$ & Average adsorbate concentration, $\mathrm{kg}_{\mathrm{l}} / \mathrm{kg}_{\mathrm{s}}$ \\
\hline W & Local adsorbate concentration, $\mathrm{kg}_{\mathrm{l}} / \mathrm{kg}_{\mathrm{s}}$ \\
\hline \multicolumn{2}{|c|}{ Greek symbols } \\
\hline$\rho$ & Density, $\mathrm{kg} / \mathrm{m}^{3}$ \\
\hline$\Delta H_{\text {ads }}$ & Heat of adsorption, $\mathrm{J} / \mathrm{kg}$ \\
\hline$\phi$ & A dependent variable \\
\hline$\varphi$ & Porosity \\
\hline$\lambda$ & Thermal conductivity, $\mathrm{W} / \mathrm{mK}$ \\
\hline \multicolumn{2}{|c|}{ Subscripts } \\
\hline i & Inner \\
\hline$l$ & Adsorbate \\
\hline 0 & Outer \\
\hline s & Adsorbent \\
\hline$v$ & Adsorptive \\
\hline$\infty$ & Equilibrium \\
\hline
\end{tabular}

compact adsorbent beds. The adsorbent bed is a cylindrical and coated type. They declared that the developed model allows an accurate description of heat and mass transfer for consolidated type adsorbents. Sun et al. [13] performed a theoretical analysis of coupled heat and mass transfer in a cylindrical adsorbent bed heated by an external fluid for zeolite $13 \mathrm{X}$-water and zeolite $13 \mathrm{X}$-ammonia pairs. The energy equation for heating fluid and tube, heat and mass balances for the adsorbent bed and Ergun's equation are non-dimensionalized in their study. Moreover, Chahbani et al. [14] investigated the effects of mass transfer kinetics on the performance of adsorption heat pump systems and they declared that restoring to the instantaneous equilibrium or LDF models instead of solid diffusion model can lead to erroneous simulation results.

In this study, heat and mass transfer in a granular adsorbent bed for an isobaric adsorption process is investigated numerically. The approach of present non-dimensional study is different than the approaches reported in literature [11-13]. Under the performed assumptions, nine independent variables which effect heat and mass transfer in the bed are combined only in two independent variables as $G$ and $\Gamma$. The heat transfer equation for the adsorbent bed and equation of the mass transfer for adsorbent granule are nondimensionalized. The corresponding initial and boundary conditions are also non-dimensionalized and the solution for the set of governing equation is obtained. Finite difference method is employed to solve the governing equations. The effects of $G$ and $\Gamma$ parameters on local and average temperatures and adsorbate concentration in the adsorbent bed for the adsorption process are studied. Moreover, a study on the comparison of three models used to simulate mass transfer through an adsorbent granule as instantaneous equilibrium, linear driving force (LDF), and solid diffusion models is performed and the obtained results based on $G$ and $\Gamma$ parameters are discussed.

\section{The considered adsorbent bed}

Fig. 1 shows the schematic view of the analyzed annulus adsorbent bed filled with the adsorbent granules. The adsorbent bed has a cylindrical shape. The adsorptive can easily flow from the inner surface, $R=R_{\mathrm{i}}$, toward the outer surface, $R=R_{\mathrm{o}}$. The upper and bottom surfaces of the adsorbent bed are insulated and the transfer of heat and mass occurs only in a radial direction. The thermal resistance of the metal casing is neglected. The study is performed in silica gelwater pair and for adsorbent bed with $R_{\mathrm{o}} / R_{\mathrm{i}}=2$.

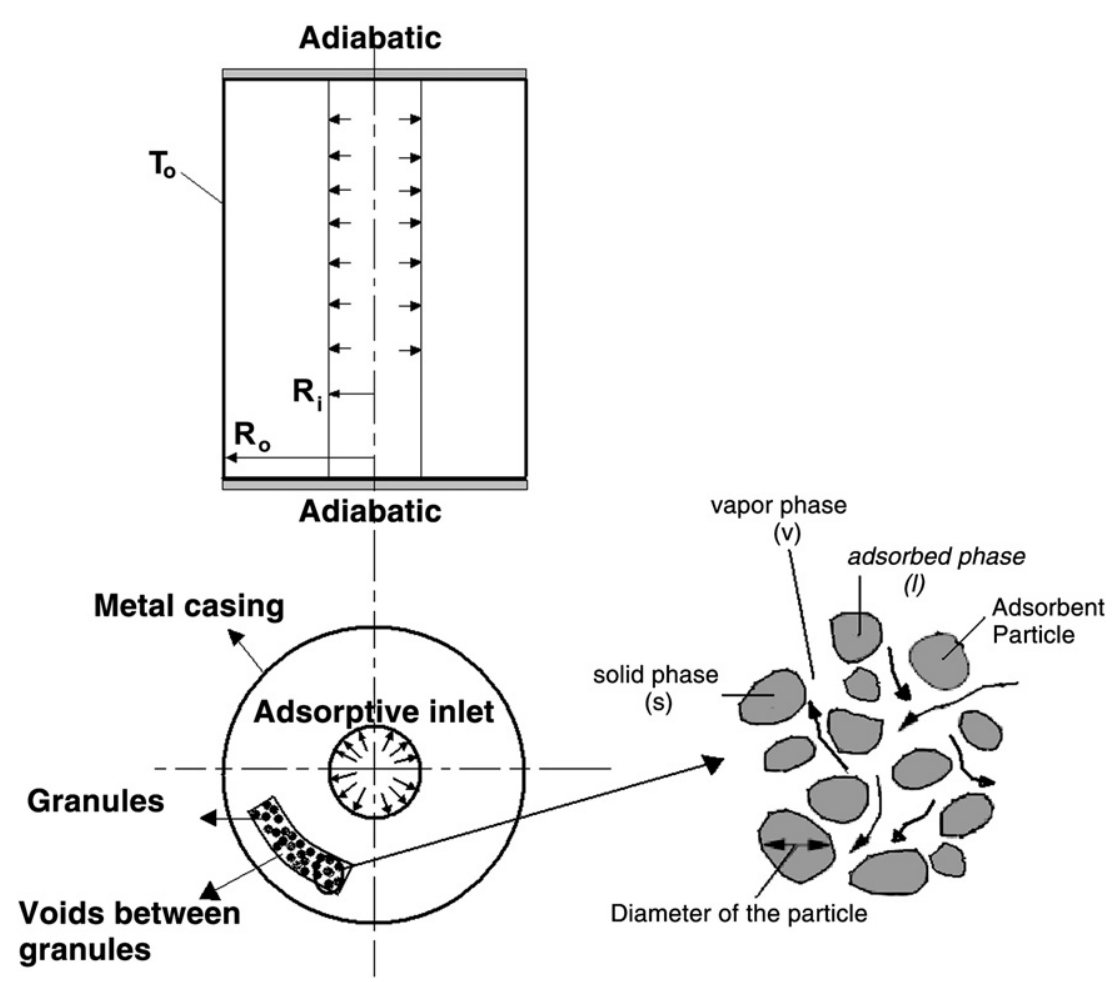

Fig. 1. The schematic view of analyzed annular adsorbent bed filled with the adsorbent granules. 


\section{Governing equations}

The mechanisms of heat and mass transfer in a granular adsorbent bed are coupled and complex, hence some assumptions have to be made to pose the governing equations. The assumptions made in this study are: 1) the pressure distribution in the bed is uniform and the adsorptive can be transferred rapidly between particles, 2) the adsorbent bed consists of uniform size adsorbent particles and the bed porosity is constant, 3 ) the adsorptive and adsorbent granules are in thermodynamic equilibrium, 4) thermal resistance within the adsorbent granule is neglected, 5) thermal properties of the adsorbent, adsorptive and adsorbate are constant, 7) heat transfer rate at $R=R_{\mathrm{i}}$ is negligible, and 8) wall thermal resistance between the bed surface and granule is not considered. Under the above assumptions, heat transfer equation for the adsorbent bed can be written as:

$\frac{\partial T}{\partial t}=\alpha_{\text {eff }} \frac{1}{R} \frac{\partial}{\partial R}\left(R \frac{\partial T}{\partial R}\right)+\frac{(1-\varphi) \rho_{\mathrm{s}}}{\left(\rho C_{\mathrm{p}}\right)_{\mathrm{eff}}} \Delta H_{\mathrm{ads}} \frac{\partial \bar{W}}{\partial t}$

where $\left(\rho C_{\mathrm{p}}\right)_{\text {eff }}$ and $\alpha_{\text {eff }}$ are the effective thermal capacitance and effective thermal diffusivity of the adsorbent bed. The effect of adsorption in the granule is contributed by $\partial \bar{W} / \partial t$ in Eq. (1).

Since interparticle mass transfer resistance is assumed negligible and adsorptive pressure between particles does not vary during adsorption process, there is no need to write mass transfer equation for adsorptive flow through the bed. However, a relation is required for the determination of adsorption rate in the adsorbent particle. There are three models used to describe adsorptive transfer in an adsorbent particle: instantaneous equilibrium, linear driving force (LDF), and solid diffusion models. In the instantaneous equilibrium mass transfer model, the adsorptive transfer within the particle is assumed sufficiently rapid such that almost no concentration gradient occurs in the adsorbent particle. The adsorbate concentration in the adsorbent particle is almost uniform and it is equal to the adsorbate concentration at the surface of the particle which is at equilibrium state. Mathematically, the instantaneous equilibrium model can be written as;

$\frac{\partial \bar{W}}{\partial t}=\frac{\partial \bar{W}_{\infty}}{\partial t}$

where $\bar{W}$ and $\bar{W}_{\infty}$ are the average adsorbate concentration in the adsorbent particle and equilibrium adsorbate concentration.

The second approach for the determination of adsorbate change in an adsorbent particle is the LDF model. According to this model, the change of mean adsorbate concentration with time is proportional to the difference between the adsorbed and equilibrium concentrations:

$\frac{\partial \bar{W}}{\partial t}=\frac{15 D_{\text {eff }}}{r_{\mathrm{p}}^{2}}\left(\bar{W}_{\infty}-\bar{W}\right)$

where $D_{\text {eff }}$ and $r_{\mathrm{p}}$ represent effective diffusivity and radius of adsorbent particle.
The solid diffusion model is based on Fick's law and the following partial differential equation should be solved to obtain the variation of local adsorbate concentration with time in the particle:

$\frac{\partial W}{\partial t}=\frac{1}{R^{2}} \frac{\partial}{\partial R}\left(R^{2} D_{\text {eff }} \frac{\partial W}{\partial R}\right)$.

Then, the change of mean adsorbate concentration of the particle with time is obtained by integration of local adsorbate concentration over the particle volume:

$\frac{\partial \bar{W}}{\partial t}=\frac{\partial}{\partial t}\left(\frac{\int_{V} W(r, t) d V}{V}\right)$

The surface of adsorbent particle is at equilibrium condition. The following dimensionless parameters are defined to obtain the dimensionless form of the governing equations (Eqs. (1-4))

$R^{*}=\frac{R}{R_{\mathrm{i}}}, \theta=\frac{T-T_{\mathrm{ref}}}{\Delta T}, \tau=\frac{\alpha_{\mathrm{eff}} t}{R_{\mathrm{i}}^{2}} ; W^{*}=\frac{W-W_{\mathrm{ref}}}{\Delta W} ; r^{*}=\frac{r}{r_{\mathrm{p}}}$

The definitions of $W_{\text {ref }}$ and $\Delta W$ depend on the process. Fig. 2 shows an isobaric adsorption process on Clapeyron diagram. The adsorption process is started when the adsorbate concentration in the adsorbent bed is $W_{\mathrm{d}}$ and bed temperature is at $T_{\mathrm{d}}$. The process is finished when the adsorbate concentration is attained to $W_{\mathrm{a}}$ while the bed temperature is decreased to $T_{\mathrm{a}}$. For adsorption process, $W_{\text {ref }}$ and $\Delta W$ can be defined as $W_{\mathrm{d}}$ and $\left(W_{\mathrm{a}}-W_{\mathrm{d}}\right)$, respectively. Similarly, $T_{\text {ref }}$ and $\Delta T$ in Eq. (6) are $T_{\mathrm{a}}$ and $\left(T_{\mathrm{d}}-T_{\mathrm{a}}\right)$. By using the above dimensionless parameters, the dimensionless form of heat transfer equation for the bed become as:

$\frac{\partial \theta}{\partial \tau}=\frac{1}{R^{*}} \frac{\partial}{\partial R^{*}}\left(R^{*} \frac{\partial \theta}{\partial R^{*}}\right)+G \frac{\partial \bar{W}^{*}}{\partial \tau}$

while the dimensionless forms of three mass transfer model for adsorbent particle are:

$\frac{\partial \bar{W}^{*}}{\partial \tau}=\frac{\partial \bar{W}_{\infty}^{*}}{\partial \tau}$

$\frac{\partial \bar{W}^{*}}{\partial \tau}=15 \Gamma\left(\bar{W}_{\infty}^{*}-\bar{W}^{*}\right)$

$\frac{\partial \bar{W}^{*}}{\partial \tau}=\frac{\Gamma}{R^{* 2}} \frac{\partial}{\partial R^{*}}\left(R^{* 2} \frac{\partial \bar{W}^{*}}{\partial R^{*}}\right)$

where $G$ and $\Gamma$ in the above equations are dimensionless independent parameters and they are defined as:

$G=\frac{\rho_{\mathrm{s}} \Delta H_{\mathrm{ads}} \Delta \bar{W}(1-\varphi)}{\left(\rho C_{\mathrm{p}}\right)_{\mathrm{eff}} \Delta T}$
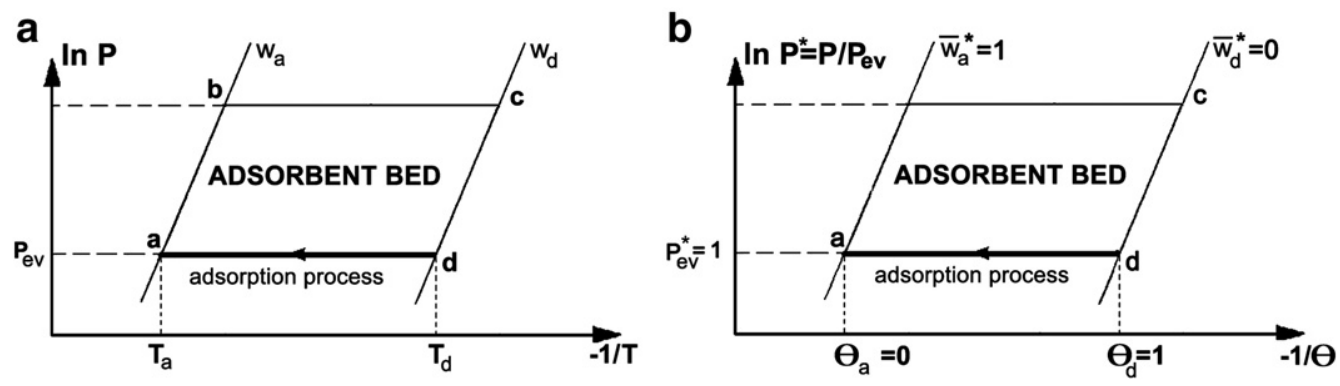

Fig. 2. A schematic view of the adsorption process on Clapeyron diagram, (a) dimensional isoster, (b) dimensionless isoster. 
$\Gamma=\frac{D_{\text {eff }} / r_{\mathrm{p}}^{2}}{\alpha_{\text {eff }} / R_{\mathrm{i}}^{2}}$

The dimensionless parameter $G$ represents the ratio of heat of adsorption to the sensible stored heat. The $\Gamma$ parameter refers to the ratio of mass transfer diffusion in the radial direction of adsorbent particle to the heat transfer diffusion in the radial direction of the adsorbent bed.

In order to solve the mass transfer equation for the particle, a relation for equilibrium state must be known. Hence, we need an additional equation for the determination of equilibrium concentration (i.e. $\bar{W}_{\infty}^{*}$ ) for the given adsorptive pressure and temperature. Fig. 2(a) shows a schematic view of the variation of pressure with temperature for silica gel-water pair for equilibrium state. The following isotherm equation can be used to determine equilibrium concentration for the given pressure and temperature [15-17]:

$\bar{W}_{\infty}=k\left(P / P_{\mathrm{S}}\right)^{1 / n}$

where $k$ and $n$ are constants and depend on adsorbent-adsorbate pair. For the silica gel-water pair considered in this study the values of $k$ and $n$ are 0.552 and 1.6, respectively. The symbol $P_{\mathrm{s}}$ represents saturation pressure at the considered temperature. Since the dimensionless forms of the governing equations are solved in this study, the dimensionless form of the adsorption equilibria is also required. The dimensionless form of the adsorption equilibria was found by numerical methods in the present study. A schematic view of dimensionless adsorption equilibria is shown in Fig. 2(b).

Some values of $G$ and $\Gamma$ for silica gel-water, active carbonmethanol, and zeolite 13X-water pairs are shown in Table 2 by using the thermophysical properties of these pairs at $53.5^{\circ} \mathrm{C}$ presented in Table 1 [18-23]. In this study, the effective thermal capacity and thermal conductivity are calculated by using the following relations:

$\left(\rho C_{\mathrm{p}}\right)_{\mathrm{eff}}=(1-\varphi)\left[\left(\rho C_{\mathrm{p}}\right)_{\mathrm{s}}+\rho_{\mathrm{s}} C_{\mathrm{pl}} \bar{W} \mid+\varphi\left(\rho C_{\mathrm{p}}\right)_{\mathrm{v}}\right.$

$\lambda_{\text {eff }}=(1-\varphi) \lambda_{\mathrm{s}}+\varphi \lambda_{\mathrm{v}}$

As seen from Table 2, the particle radiuses are considered as 0.1, 0.5 and $1 \mathrm{~mm}$, and consequently the values of $G$ and $\Gamma$ are changed. Based on this table, the values of $G$ and $\Gamma$ are changed from 1 to 100 and from $10^{-5}$ to 1 , respectively. The initial condition for the problem can be written as:

$\tau=0 ; \quad \theta=1 ; \bar{W}^{*}=0$

Table 1

Thermophysical properties of three adsorbent-adsorbate pairs at $T_{\text {mean }}=53.5^{\circ} \mathrm{C}$.

\begin{tabular}{|c|c|c|c|}
\hline & $\begin{array}{l}\text { Silica gel- } \\
\text { water }\end{array}$ & $\begin{array}{l}\text { Active carbon- } \\
\text { methanol }\end{array}$ & $\begin{array}{l}\text { Zeolite13X- } \\
\text { water }\end{array}$ \\
\hline Density of adsorbent $(\mathrm{s})\left(\mathrm{kg} / \mathrm{m}^{3}\right)$ & 670 & 460 & 620 \\
\hline Density of adsorptive (v) & 0.09838 & 0.78715 & 0.09838 \\
\hline Density of adsorbate $(l)$ & 986.19 & 758.73 & 986.19 \\
\hline$C_{\mathrm{p}}$ of adsorbent $(\mathrm{s})(\mathrm{kJ} / \mathrm{kg} \mathrm{K})$ & 0.88 & 0.93 & 0.836 \\
\hline$C_{\mathrm{p}}$ of adsorptive $(\mathrm{v})$ & 1.907 & 0.65 & 1.907 \\
\hline$C_{\mathrm{p}}$ of adsorbate $(l)$ & 4.183 & 2.73 & 4.183 \\
\hline $\begin{array}{l}\text { Thermal conductivity of } \\
\text { adsorbent }(\mathrm{s})(\mathrm{W} / \mathrm{mK})\end{array}$ & 0.198 & 0.11 & 0.2 \\
\hline $\begin{array}{l}\text { Thermal conductivity of } \\
\text { adsorptive }(\mathrm{v})\end{array}$ & 0.02146 & 0.01818 & 0.02146 \\
\hline Thermal conductivity of adsorbate $(l)$ & 0.647 & 0.1944 & 0.647 \\
\hline Heat of adsorption $(\mathrm{kJ} / \mathrm{kg})$ & 2369 & 1122 & 2369 \\
\hline
\end{tabular}

Table 2

Values of $G$ and $\Gamma$ for an adsorbent bed filled with adsorbent particle when $\varphi=0.35$, $R_{\mathrm{i}}=10 \mathrm{~mm}, T_{\text {mean }}=53.5^{\circ} \mathrm{C}, D_{\text {eff }}=4.97 \mathrm{E}-11 \mathrm{~m}^{2} / \mathrm{s}, \bar{W}=0.1$ and $\Delta T=10^{\circ} \mathrm{C}$.

\begin{tabular}{cllllll}
\hline & $\begin{array}{l}r_{\mathrm{p}} \\
(\mathrm{m})\end{array}$ & $\begin{array}{l}\left(\rho C_{\mathrm{p}}\right)_{\text {eff }} \\
(\mathrm{kJ} / \mathrm{kg} \mathrm{K})\end{array}$ & $\begin{array}{l}\lambda_{\text {eff }} \\
(\mathrm{W} / \mathrm{mK})\end{array}$ & $\begin{array}{l}\alpha_{\text {eff }} \\
\left(\mathrm{m}^{2} / \mathrm{s}\right)\end{array}$ & $G$ & $\Gamma$ \\
\hline Silica gel-water & 0.0001 & 565.475 & 0.136 & 0.000241 & 36.490 & $2.06 \mathrm{E}-03$ \\
& 0.0005 & 565.475 & 0.136 & 0.000241 & 36.490 & $8.25 \mathrm{E}-05$ \\
& 0.001 & 565.475 & 0.136 & 0.000241 & 36.490 & $2.06 \mathrm{E}-05$ \\
Active carbon- & 0.0001 & 278.249 & 0.078 & 0.000280 & 24.114 & $1.78 \mathrm{E}-03$ \\
methanol & 0.0005 & 278.249 & 0.078 & 0.000280 & 24.114 & $7.10 \mathrm{E}-05$ \\
& 0.001 & 278.249 & 0.078 & 0.000280 & 24.114 & $1.78 \mathrm{E}-05$ \\
Zeolite 13X-water & 0.0001 & 336.974 & 0.138 & 0.000408 & 56.664 & $1.22 \mathrm{E}-03$ \\
& 0.0005 & 336.974 & 0.138 & 0.000408 & 56.664 & $4.87 \mathrm{E}-05$ \\
& 0.001 & 336.974 & 0.138 & 0.000408 & 56.664 & $1.22 \mathrm{E}-03$ \\
\hline
\end{tabular}

The boundary conditions for the problem are:

$R^{*}=1 ; \quad \partial \theta / \partial R^{*}=0$

$R^{*}=R_{\mathrm{o}}^{*} / R_{\mathrm{i}}^{*} ; \quad \theta=0$

\section{Solution method}

Finite difference method is used to solve the governing equations. By substituting of initial values into the dependent variables ( $\theta$ and $\left.\bar{W}^{*}\right)$, heat transfer equation for the bed, Eq. (7), is solved to determine local dimensionless temperature in the adsorbent bed. Then, by using the dimensionless temperature values, mass transfer equations (Eqs. (8)-(10)) are solved to calculate dimensionless adsorbate concentration in the particle. An inner iteration is used to obtain the simultaneous solution of heat transfer equation for the bed and mass transfer equation for the particle. Then, the time is increased. For solid diffusion model (Eq. (10)), after obtaining local adsorbate concentration in the adsorbent particle, the average of adsorbate concentration in the particle was determined. The following convergence criterion was used for inner iterations:

$\left|\frac{\phi^{n+1}-\phi^{n}}{\Delta \tau}\right|<10^{-8}$

where $\phi$ represents $\bar{W}^{*}$ and $\theta$. The procedure is continued until the adsorbate concentration and temperature reached to final values as $\bar{W}^{*}=0.9995$ and $\theta=0.0005$.

Fig. 3 shows the variation of average dimensionless temperature versus dimensionless time for three different numbers of nodes as 6 ,

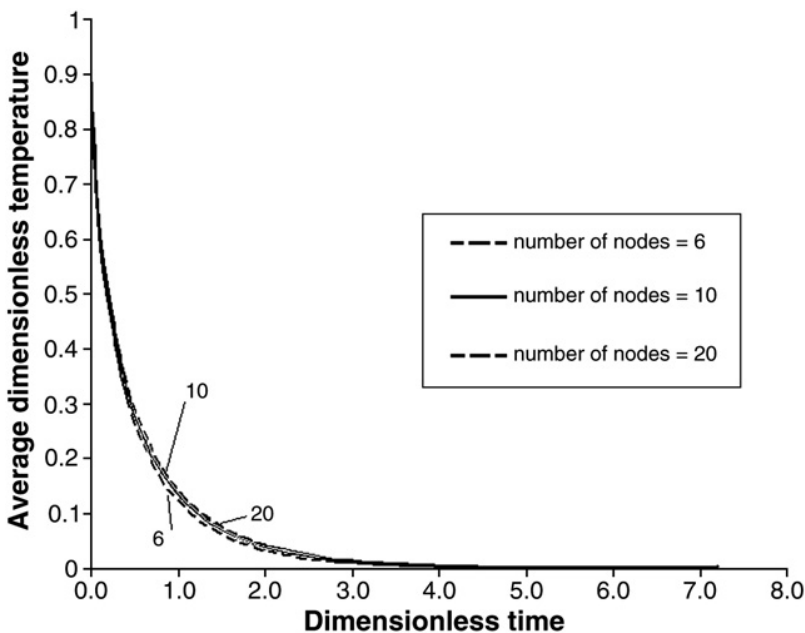

Fig. 3. The variation of average dimensionless temperature versus dimensionless time for three different number of nodes. 
10 and 20 when $G=1$ and $\Gamma=1$. As is seen, the variations of the average dimensionless temperature with time for all of the three different numbers of nodes are close to each other. To save the computational time, the number of nodes was taken as 10 in the present study and it is sufficient to obtain accurate results.

\section{Result and discussion}

The non-dimensionalized governing equations reduce the number of independent parameters to two parameters as $G$ and $\Gamma$. It should be mentioned that the results of the present study is valid for adsorbent bed with $R_{\mathrm{o}} / R_{\mathrm{i}}=2$.The parameter $G$ is the ratio of heat of adsorption generated in the adsorbent bed to the sensible stored heat during the adsorption process. Large values of $G$ signify high heat of adsorption compared to the sensible heat stored by the adsorbent. The $\Gamma$ parameter refers to the ratio of mass diffusion in radial direction of adsorbent particle to the diffusion of heat in radial direction of adsorbent bed. The high value of $\Gamma$ shows that the diffusion of mass in the radial direction of the adsorbent particle is faster than the transfer of heat in radial direction of the adsorbent bed. For the high values of $\Gamma$, the adsorptive can be adsorbed immediately in the adsorbent particle and the adsorbate concentration in the adsorbent particle may be expected to be almost uniform. In this case, the mass transfer resistance in the particle can be neglected; therefore heat transfer resistance through the adsorbent bed controls the adsorption process.
For low values of $\Gamma$, the propagation of heat in the adsorbent bed is faster than the adsorptive transfer in the adsorbent particle. Hence, mass transfer resistance in the adsorbent particle is expected to control the adsorption process.

Fig. 4 shows the change of averages of dimensionless adsorbate concentration and temperature with dimensionless time for two different values of $G$ and $\Gamma$. The results were obtained by LDF method. As shown in Fig. 4(a), the average of dimensionless temperature decreases with time while the average of adsorbate concentration increases when $G=1$ and $\Gamma=1$. The total dimensionless time for the adsorption process for this case is around $\Delta \tau=6.95$. For low values of $\Gamma$ (i.e. $\Gamma=10^{-5}$ ) when $G=1$, the average of dimensionless temperature rapidly falls while adsorbate concentration increases slowly as seen from Fig. 4(b). By the decrease of $\Gamma$ value to $10^{-5}$, the total dimensionless time of adsorption process considerably increases and attains to 52,400 . The low value of $\Gamma$ denotes the slow mass diffusion in the particle and that's why the adsorption time is highly increased. The changes of $\bar{W}^{*}$ and $\theta$ for $G=100$ and $\Gamma=1$ are similar to those of Fig. 4(a), however the total dimensionless time of adsorption increases 61-fold due to the increase of $G$ which is a source term in Eq. (7) and the increase of $G$ value increases the period of adsorption process. Fig. 4(d) shows the variation of $\bar{W}^{*}$ and $\theta$ for $G=100$ while $\Gamma=10^{-5}$. Similar to Fig. 4(b), the decrease of $\Gamma$ signifies a lower heat transfer resistance in the adsorbent bed in radial direction and therefore the average dimensionless temperature rapidly falls. The

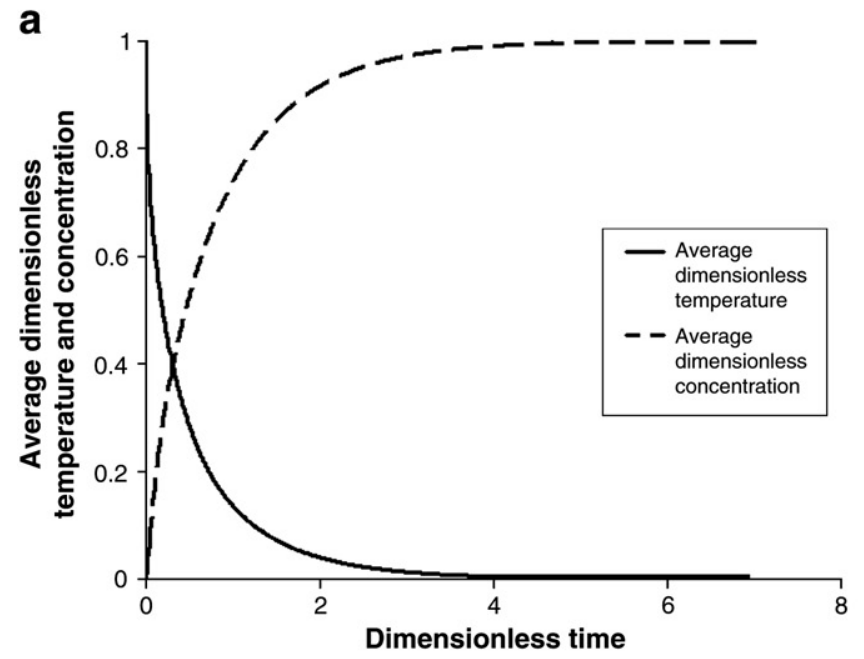

b
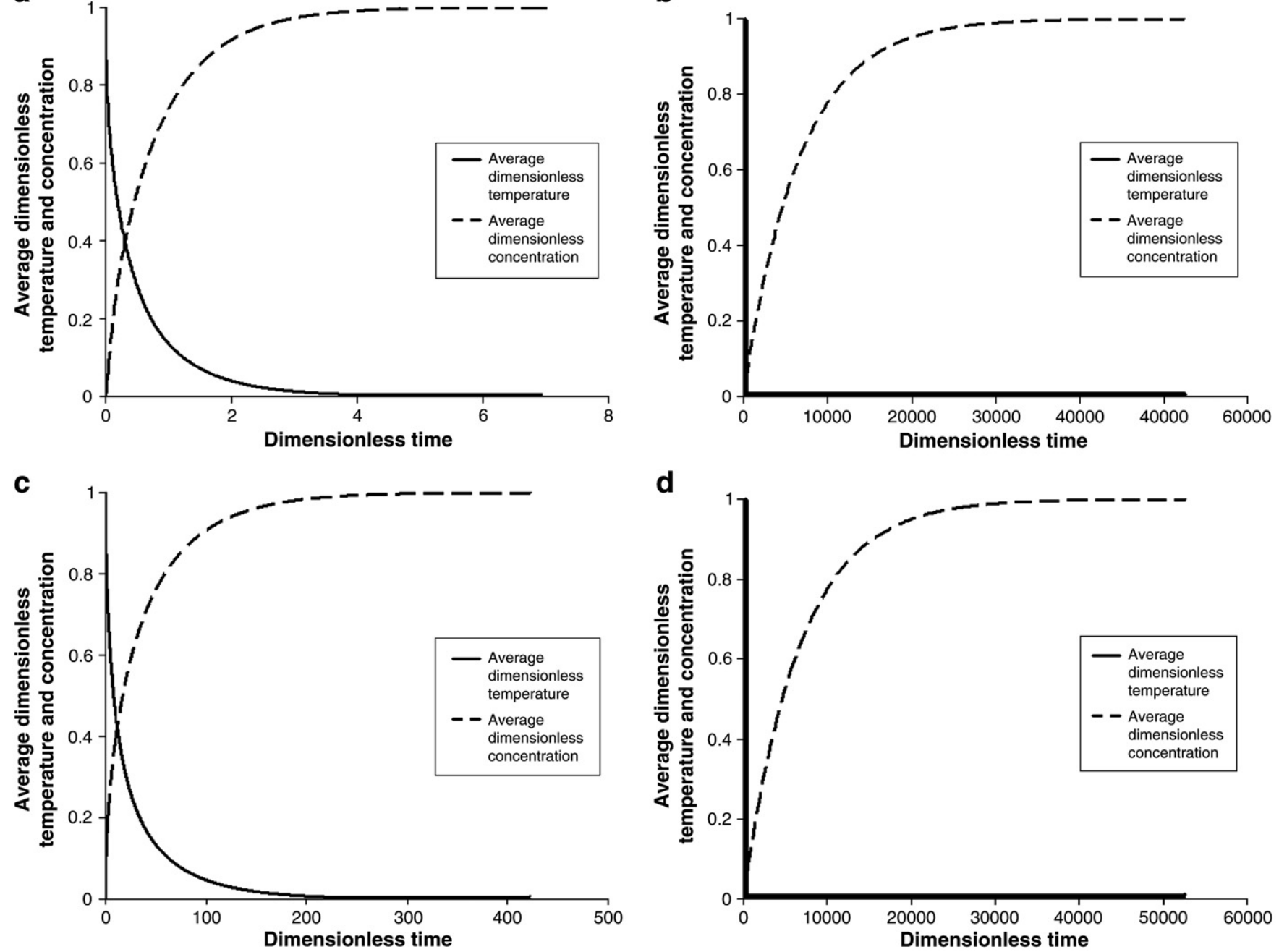

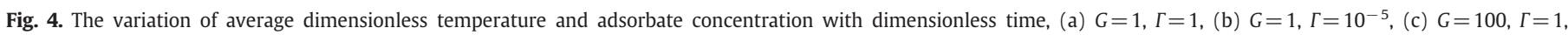
(d) $G=100, \Gamma=10^{-5}$. 


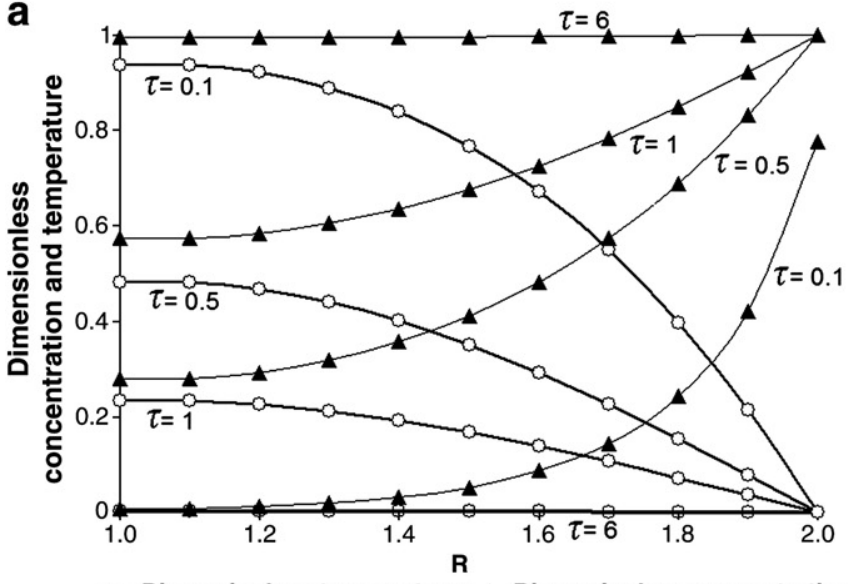

- - Dimensionless temperature - - Dimensionless concentration

C

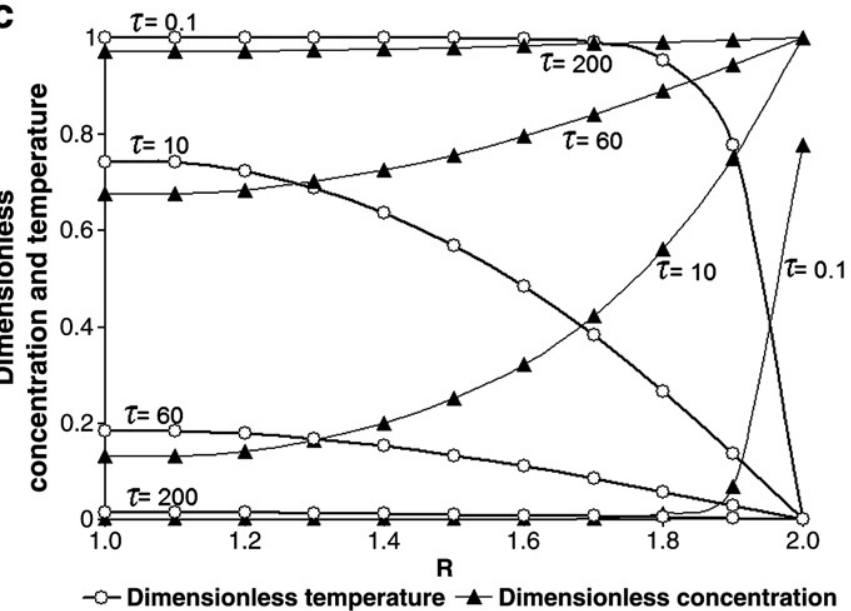

b

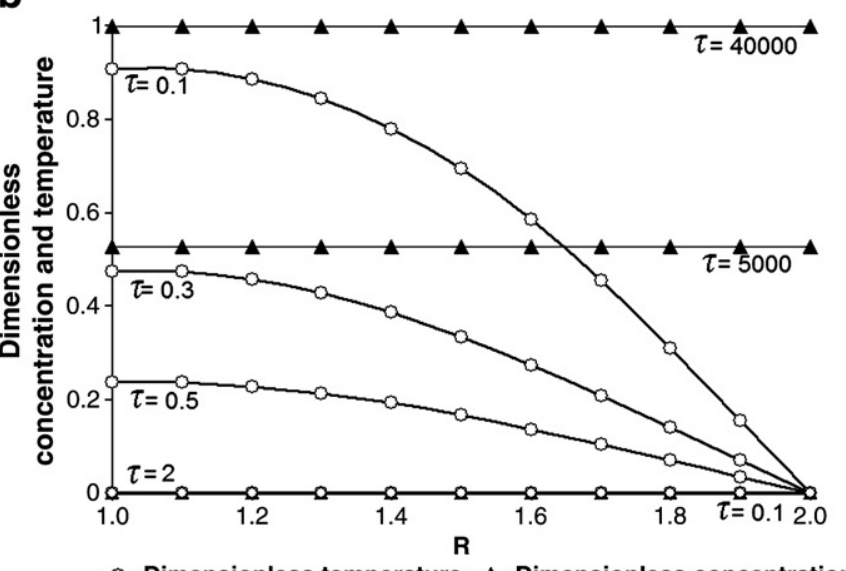

$-\infty$ Dimensionless temperature $-\downarrow$-Dimensionless concentration

d

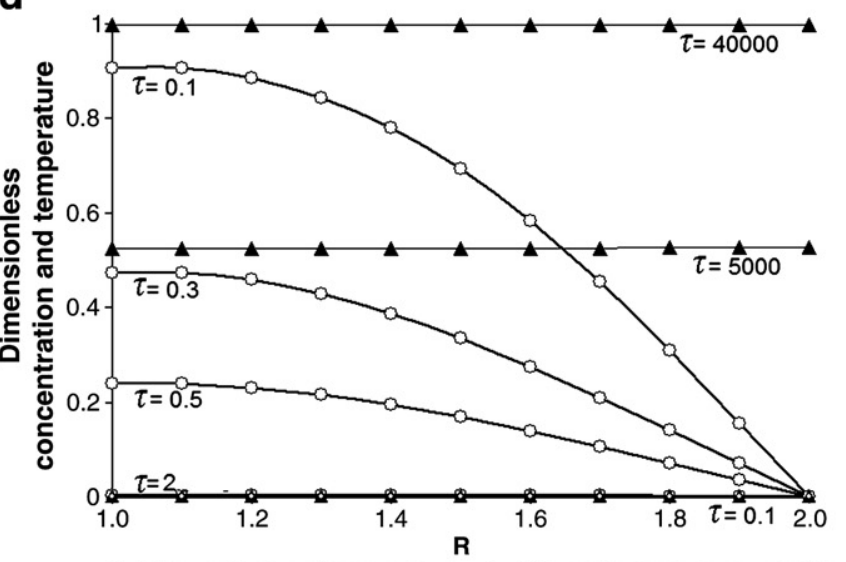

$\rightarrow$ - Dimensionless temperature $-\mathbf{A}$-Dimensionless concentration

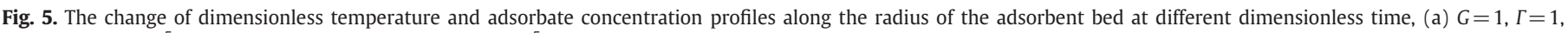
(b) $G=1, \Gamma=10^{-5}$, (c) $G=100, \Gamma=1$, (d) $G=100, \Gamma=10^{-5}$.

comparison of Fig. 4(b) and (d) shows that the increase of the $G$ value from 1 to 100 the extends the adsorption period only by $0.4 \%$.

Fig. 5 depicts the change of dimensionless adsorbate concentration and temperature profiles in the adsorbent bed for different dimensionless times for $G=1$ and 100 , and $\Gamma=10^{-5}$ and 1 . As is seen from Fig. 5(a), for $G=1$ and $\Gamma=1$, both the diffusion of heat through the adsorbent bed and diffusion of adsorptive in the adsorbent particle reach the steady state after a short period $\tau=6.95$. Fig. 5 (b) shows the variations of $\bar{W}^{*}$ and $\theta$ when $G=1$ and $\Gamma=10^{-5}$. For small values of $\Gamma$ (i.e. $\Gamma=10^{-5}$ ), the diffusion of heat through the adsorbent bed is faster than the diffusion of adsorptive in the adsorbent particle. After dimensionless time as $\tau=2$, the distribution of temperature in the adsorbent bed becomes uniform and drops to around $\theta=0$ which overlaps the $X$ axis. However, the adsorbate concentration attains to steady state after $\tau=52,400$ signifying that the low speed of adsorptive diffusion in the particle causes the increase of adsorption period. The distribution of local $\bar{W}^{*}$ and $\theta$ for $G=100$ and $\Gamma=1$ are shown in Fig. 5(c). Similar to Fig. 5(a), both the temperature and adsorbate concentration profiles in the adsorbent bed approaches the steady state at the same time however the increase of $G$ increases the period of adsorption process to $\tau=422$. The profiles of $\bar{W}^{*}$ and $\theta$ for the large value of $G$ (i.e. $G=100$ ) but for small value of $\Gamma$ (i.e. $\Gamma=10^{-5}$ ) are illustrated in Fig. 5(d). Heat transfer through the adsorbent bed is faster than mass transfer in the particle and almost uniform mass transfer profile occurs during adsorption process.

The variation of total dimensionless period of adsorption process with $\Gamma$ for $G=1$ and 100 is presented in Fig. 6 . The mass transfer resistance through the particle becomes smaller by the increase of $\Gamma$ value from $10^{-5}$ to 1 , and therefore total dimensionless period of adsorption process is decreased. The increase of $\Gamma$ from $10^{-5}$ to 1 reduces the total dimensionless adsorption period by $753 \%$ when $G=1$. For large values of $\Gamma$, mass transfer resistance is negligible and heat transfer through the bed is the main transport resistance. The similar changes of total dimensionless period with $\Gamma$ can also be observed when $G=100$. However; the rate of decrease of total

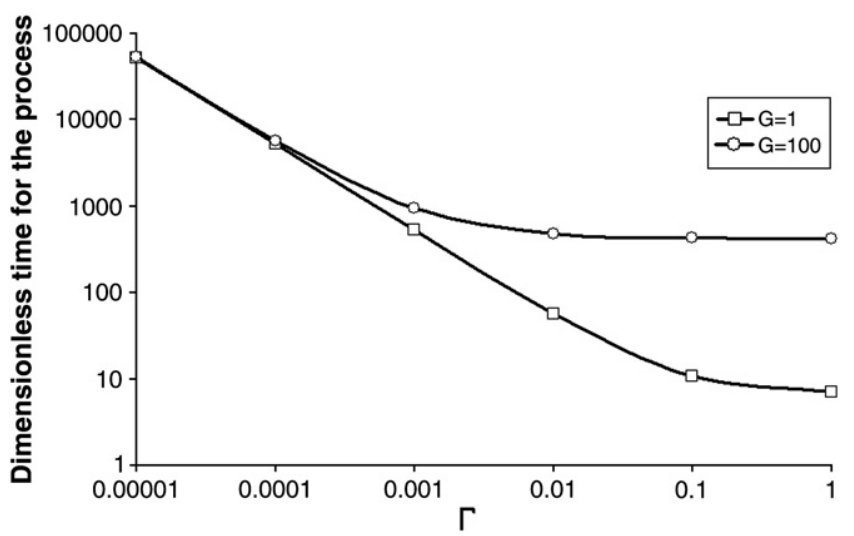

Fig. 6. The variation of total dimensionless time of the adsorption process with $\Gamma$ for $G=1$ and $G=100$. 

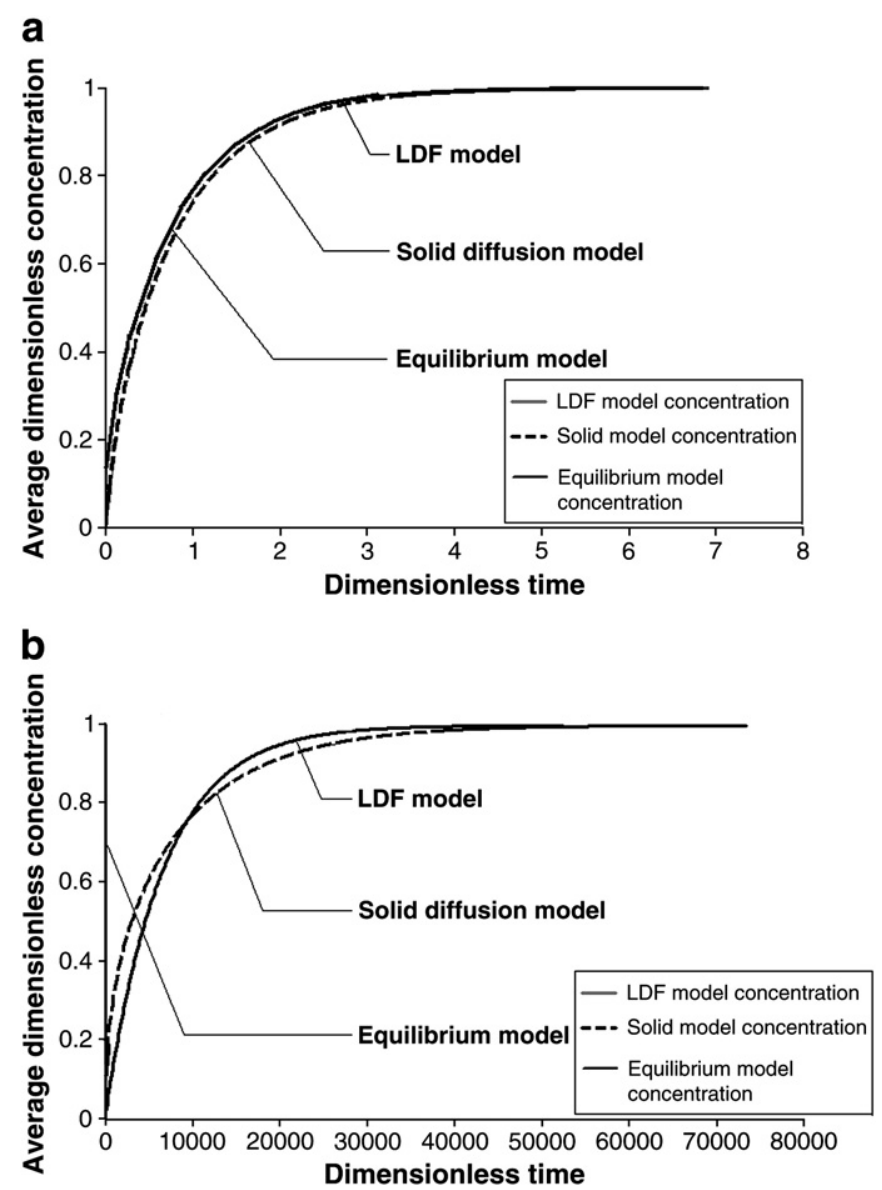

Fig. 7. Comparison of average adsorbate concentration with dimensionless time for instantaneous equilibrium, LDF and solid diffusion models, (a) $G=1, \Gamma=1$, (b) $G=1$, $\Gamma=10^{-5}$.

dimensionless period is smaller compared with that of $\Gamma=1$. The increase of the value of $G$ increases the value of source term in Eq. (7) and consequently the cooling of the adsorbent bed becomes slower.

Fig. 7 shows the comparison of average of adsorbate concentration versus dimensionless time for three mass balance models for the adsorbent particle as instantaneous equilibrium, LDF and solid diffusion models and for two different values of $\Gamma$ as $10^{-5}$ and 1 when $G=1$. As shown in Fig. 7(a), the changes of $\bar{W}^{*}$ for all three models are very close to each other when $\Gamma=1$. Therefore, all three models can be used for high values of $\Gamma$ when $G=1$. However, the variation of $\bar{W}^{*}$ with dimensionless time for instantaneous equilibrium model becomes very different than LDF and solid diffusion models when $\Gamma=10^{-5}$ as seen from Fig. 7(b). The adsorbate concentration rapidly attains to equilibrium condition for instantaneous equilibrium model and it overlaps the $Y$ axis. The changes of the average of dimensionless concentration with time for LDF and solid diffusion models are similar to each other. This figure shows that the equilibrium model cannot be used for low values of $\Gamma$, but LDF and solid diffusion models provide similar results. Although the analytical solution of solid diffusion model provides the exact solution for the changes of adsorbate concentration in the particle, the LDF model is more preferable due to saving of computational time. The obtained results show that the similar behavior observed for $G=1$ is valid when $G=100$.

\section{Conclusion}

The non-dimensionalization of the governing equations for a granular type adsorbent bed for an isobaric adsorption process reduces the number of parameters and yields two dimensionless parameters as $G$ and $\Gamma$. Under the made assumptions and based on the obtained results the following remarks can be concluded:

- For an adsorbent bed with constant $G$ value, the decrease of $\Gamma$ value causes the increase of mass transfer resistance in the particle compared to resistance of heat transfer through the adsorbent bed. Therefore, the total dimensionless period for adsorption process is increased.

- For an adsorbent bed with constant $\Gamma$ value, the increase of $G$ value increases the value of source term in the dimensionless heat transfer equation, and consequently the dimensionless period of process increases.

- For low values of $\Gamma$ (i.e. $\Gamma=10^{-5}$ ), the change of $G$ does not highly influence the total dimensionless period of the process but for high values of $\Gamma$ (i.e. $\Gamma=1$ ) the total dimensionless period of adsorption process considerably decreases with a decrease of $G$ value.

- For high values of $\Gamma$ (i.e. $\Gamma=1$ ), the solutions of the governing equations for all three models of mass transfer within a particle (instantaneous equilibrium, LDF and solid diffusion models) are very close to each other. However, for low values of $\Gamma$ (i.e. $\Gamma=10^{-5}$ ) the results of instantaneous equilibrium model becomes too different than those of LDF and solid diffusion models signifying that the instantaneous equilibrium model cannot be used for problems with low values of $\Gamma$.

- For the range of $\Gamma$ and $G$ studied in the present work, the results of LDF and solid diffusion models are found close to each other.

The present parametric study can be extended to two or three dimensional problems with different initial and boundary conditions to observe the effects of $G$ and $\Gamma$ parameters on heat and mass transfer in a granular adsorbent bed better.

\section{References}

[1] D.J. Close, R.V. Dunkle, Use of adsorbent beds for energy storage in drying and heating systems, Solar Energy 19 (1977) 233.

[2] D.I. Tchernev, Solar applications of natural zeolites, Natural Zeolites Occurrence Properties and Use, Oxford, 1976.

[3] D.I. Tchernev, The use of zeolites for solar cooling, Proc. 5th Inter Conference on Zeolites, Naples, Italy, 1980.

[4] S. Ülkü, M. Mobedi, Adsorption in energy storage, Proceedings of the NATO Advanced Study Institute on Energy Storage Systems, Series E. Applied Science 167 (1989) 487-507.

[5] K.C. Leong, Y. Liu, Numerical study of a combined heat and mass recovery adsorption cooling cycle, International Journal of Heat and Mass Transfer 47 (2004-1) 4761-4770.

[6] H. Demir, M. Mobedi, S. Ülkü, Effects of porosity on heat and mass transfer in a granular adsorbent bed, International Communications in Heat and Mass Transfer 36 (2009) 372-377.

[7] B.B. Saha, A. Chakraborty, S. Koyama, Y.I. Aristov, A new generation cooling device employing $\mathrm{CaCl}_{2}$ in silica gel water system, International Journal of Heat and Mass Transfer 52 (2009) 516-524.

[8] N. Ben Amar, L.M. Sun, F. Meunier, Numerical analysis of adsorptive temperature wave regenerative heat pump, Applied Thermal Engineering 16 (1996) 405-418.

[9] A. Haiji, Z. Lavan, Numerical solution of nonlinear hyperbolic equations governing a regenerative closed-cycle adsorption cooling and heating system, Numerical Heat Transfer: Part A, Applications 21 (1992) 1-19.

[10] K.C. Leong, Y. Liu, System performance of a combined heat and mass recovery adsorption cooling cycle: a parametric study, International Journal of Heat and Mass Transfer 49 (2006) 2703-2711.

[11] G. Cacciola, A. Hajji, G. Maggio, G. Restruccia, Dynamic simulation of a recuperative adsorption heat pump, Energy 18 (1993) 1125-1137.

[12] L. Marletta, G. Maggio, A. Freni, M. Ingrasciotta, G. Restuccia, A non-uniform temperature non-uniform pressure dynamic model of heat and mass transfer in compact adsorbent beds, International Journal of heat and Mass Transfer 45 (2002) 3321-3330.

[13] L.M. Sun, N. Ben Amar, F. Meunier, Numerical study on coupled heat and mass transfers in an adsorber with external fluid heating, Heat Recovery Systems 15 (1995) 19-29.

[14] H.M. Chahbani, J. Labidi, J. Paris, Effect of mass transfer kinetics on the performance of adsorptive heat pump systems, Applied Thermal Engineering 22 (2002) 23-40.

[15] A. Sakoda, M. Suzuki, Fundamental study on solar powered adsorption cooling system, Journal of Chemical Engineering Japan 17 (1984) 52-57. 
[16] A. Sakoda, M. Suzuki, Simultaneous transport of heat and adsorbate in closed type adsorption cooling system utilizing solar heat, Journal of Solar Energy EngineeringTransactions of ASME 108 (1986) 239-245.

[17] Y. Liu, K.C. Leong, Numerical study of a novel cascading adsorption cycle, International Journal of Refrigeration 29 (2006) 250-259.

[18] F.P. Incropera, D.P. Dewitt, Fundamentals of Heat and Mass Transfer, 3rd Ed.Wiley, New York, 1996.

[19] R.H. Perry, D. Green, Perry's Chemical Engineering Handbook, 6th EdMcGraw Hill, 1984.

[20] W.H. Cheng, H.H. Kung, Methanol Production and Use, Marcel Dekker Inc, 1994.
[21] K.C. Leong, Y. Liu, Numerical modeling of combined heat and mass transfer in the adsorbent bed of a zeolite/water cooling system, Applied Thermal Engineering (2004) 2359-2374.

[22] L.W. Wang, R.Z. Wang, Z.S. Lu, C.J. Chen, K. Wang, J.Y. Wu, The performance of two adsorption ice making test units using activated carbon and a carbon composite as adsorbents, Carbon 44 (2006) 2671-2680.

[23] N.V. Ogueke, E.E. Anyanwu, Design improvements for a collector/generator/ adsorber of a solid adsorption solar refrigerator, Renewable Energy 33 (2008) $2428-2440$ 